Japanese Psychological Research
1965, Vol. 7, No. 4, 151-162

\title{
A STUDY ON THE EFFECTIVENESS OF SUPERVISORY PATTERNS IN A JAPANESE HIERARCHICAL ORGANIZATION ${ }^{1}$
}

\author{
JYUJI MISUMI AND TOSHIAKI TASAKI ${ }^{2}$
}

Kyushu University

\begin{abstract}
This study was designed to investigate what types of leader behaviors were effective in group productivity and morale. With the goal achievement $(\mathrm{P})$ and the process maintenance $(\mathbf{M})$ functional dimension used as the bases, the supervisory behavior of the first-line and the second-line supervisors were operationally divided into four patterns: namely, $\mathrm{P}, \mathrm{M}, \mathrm{PM}$ and $\mathrm{pm}$ which is determined by the intensity of two functions. The questionnaire was administered to the 500 coal getters. The supervisory patterns common to the high-producing groups were found to be PM and $M$ patterns. The patterns $P$ and $p m$ were found to be common to the low-producing groups. The morale of the workers in the highproducing groups was relatively higher than that of those in the low-producing groups.
\end{abstract}

One of the major questions in the previous studies of leadership has been what types of leadership would be the most effective for the group productivity and morale.

Halpin \& Winer (1952) conducted a factor-analysis study concerning the behaviors of supervisors in a workplace, and discovered the two factors, i.e. " Consideration" and "Initiating Structure".

On the basis of this 2-factor theory, Fleishman et al. (1955), Halpin (1957), Hemphill (1957), Besco et al. (1959), Fleishman et al. (1962) examined the relationship between these factors and morale and productivity in the various organizations.

This study was supported by a Grant in Aid for Scientific Researches, Ministry of Education.

2 It must be noted that Sanshiro Shirakashi, too, is among the joint researchers for this study. It also must be added that the research was made possible by the full support and understanding of the Chuko Coal Mine Co. Ltd. With sincere thanks we hereby acknowledge the wholehearted cooperation extended by the research assistants and students of the Institute for Group Dynamics. Thanks are due to Mr. Hiromichi Ito, Information Advisor, Fukuoka American Cultural Center, who helped us with the translation of the manuscript of this paper.
These studies were made mostly with regard to the first-line supervisors.

Misumi (1960a, 1960b) conducted a field study of supervisory behaviors in a smallsized enterprise and found that a highproducing first-line supervisor is more production-centered than a low-producing first-line supervisor, while a high-producing second-line supervisor is more human relations-centered than a low-producing second-line supervisor. Also, Misumi \& Shirakashi (1966 in press) created, on a laboratory experimental basis, a hierarchical organization in which the first-line supervisors supervised the simple job of counting accurately holes in IBM cards. As a result of this study, it was found that the end result is the highest under the first-line supervisor who is both production- and human relations-centered. In other words, he is the supervisor of PM type as described in what follows.

This study proposes to verify the validity of the hypotheses of the authors' previous experimental study through applying them to a social setting of a hierarchical organization in a Japanese coal mine.

In our study, to classify the supervisory patterns, two dimensions of function are 
provided. They are the dimension of the goal achievement-centered function and the dimension of the process maintenancecentered function. The supervisory patterns may be then classified into the following four patterns by combining varying degrees of the intensity of the above two dimensions of functions (see Fig. 1). With respect to Fig. 1, Kahn (1960) suggested the similar four-celled table. This classification is basically the same as the one used in the previous experimental study.

1. Goal achievement-centered supervisory pattern with higher intensity (called P for short).

2. Process maintenance-centered supervisory pattern with higher intensity (called M for short).

3. Goal achievement and also process maintenance-centered supervisory pattern with higher intensity (called PM for short).

4. Supervisory pattern which included both goal achievement and process maintenance functions with lower intensity (called pm for short).

The function of the pattern $\mathrm{P}$ is a function of accelerating the solution of problems facing an organization or a group and increasing efficiency and productivity. To be more specific, this is the behavior of a supervisor who is strongly job-centered,

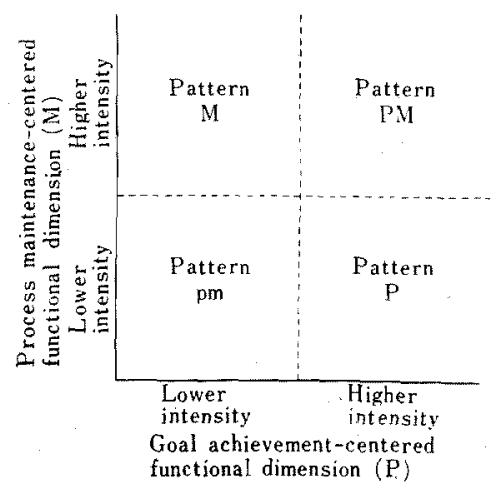

FIG. 1. The diagram showing the classification of supervisory patterns based on the intensity of the $\mathrm{P}$ and $\mathrm{M}$ functions in both dimensions. tending to take the initiative in solving problems that arise in the performance of work and to have all the rules strictly observed, but is less interested in considering human relations.

The function of the pattern $M$ is a function of allying any destructive tensions among the members of an organization or a group, thus maintaining and strengthening its human relations, ${ }^{3}$. In more specific terms, this is the type of a supervisor characterized by the human relationscentered supervisory pattern, who is open to suggestions from his subordinates, never obtrude his opinion upon them and readily respond to consultation, but is less interested in considering the task performance aspect.

PM is the behavior pattern of a supervisor strongly oriented toward task performance and human relations with higher intensity.

$\mathrm{pm}$ is the behavior pattern of a supervisor oriented toward these two functions with lower intensity.

This study was conducted to determine which of these supervisory patterns would be the most effective in terms of the group productivity and morale by an analysis of the supervisory pattern of the first-line supervisors and of their superior secondline supervisors in working groups of a coal mine.

\section{Method}

Subject. Subjects for this study were eight working groups including a total of 215 workers who were engaged in digging coal in the pit of the Fukushima Colliery operated by the Chuko Coal Mine Co. Ltd., Nagasaki prefecture. ${ }^{4}$ Each of these working groups was made up of 20 to 30 coal-getters. The first-line supervisor who supervises a working group at firsthand is called "Sekinin", or working leader. The

${ }^{3}$ As regards the functions of $\mathbf{P}$ and $M$, see chapter 25, Gartwright, D and Zander, A. Group Dynamics, Row Peterson: New York, 1960. 
"Sekinin" is elected once a year, separately for each group from among group members. He, as every other member, is paid on a contractual basis, but is authorized to supervise all other coal-getters in the group at firsthand.

As his superior officer, there is the secondline supervisor in the working group who is referred to as "Kakari-in", or officer-in-charge. The "Kakari-in" is a qualified engineer who has passed the National Examination. He is on the regular payroll of the Company and receives a fixed salary. ${ }^{5}$ The responsibilities of the "Sekinin" include (1) job assignment at the coal face, (2) determination of the working procedure, (3) determination of the daily working quota and (4) the "budate", or the rating of the proficiency of each worker. The wage for each worker is decided on the basis of "budate" .

The "Kakari-in" is virtually the leader of the working group. The main function of the "Kakari-in" is (1) to assume the overall responsibility for the safety in the pit, (2) provide

4 The Chuko Coal Mine Co. Ltd., presently capitalized at 250 -million ( 360 to the dollar), has 1,556 employees. The company operates three collieries. Although this company is classed as mediumsized coal mine company, it is virtually larger than some of those classified into the larger bracket. In terms of output, the Chuko Coal Mine Co. Ltd. ranks second in the medium-sized bracket. When this company was first founded in 1955, its annual output was 350,000 tons, with its monthly per capita output being 13 tons and the average per capita monthly wage being $¥ 12,217$. As of 1963 , at which year this study was conducted, the figures increased to 660,000 tons, 41 tons and 30,071 respectively. Its operations have grown to the point of ranking with some of the companies topping the list of the large company bracket. The Fukushima Colliery, which was used as the subject for this study, is located in Fukushima Town, Kita-Matsuura Gun, Nagasaki Prefecture. This town, with a population of 11,000 is situated on a $16 \mathrm{sq} \mathrm{km}$-island in the Imari Bay. Over $40 \%$ of its working population are associated one way or another with the Chuko Coal Mine Co. Ltd., with the remainder made up of farmers $(20 \%)$ and others.

"The status of "Sekinin" is a miner and that of "Kakari-in" is a staff employee. technical guidance to all the coal-getters including the "Sekinin" and (3) check on all the decisions made by the " Sekinin". Particularly, any decision concerning "budate" is subject to approval of the "Kakari-in".

The survey was conducted originally with 19 working groups involving a total of 500 workers. As explained later, however, those working groups that could not distinguish high producing groups and low producing ones were ommited. Consequently, as mentioned before, the results obtained from the remaining eight working groups involving a total of 215 workers were eventually tabulated for this study.

Procedure for survey. The survey was conducted in July, 1963 by means of the group interview method, using questionnaire.

Measurement of the supervisory behaviors of the "Sekinin" (first-line supervisor) and the "Kakariin" (second-line supervisor). The supervisory behaviors of the respective supervisors were measured with regard to the "job-centered supervisory" function (P) and the "human relations-centered supervisory" function (M). Each of the subjects was requested to rate the supervisory behaviors of their "Sekinin" and "Kakari-in " on the basis of a 5-point scale with regard to the below-mentioned questions. In other words, their supervisory behaviors were rated by cognitions of their subordinates.

Questions concerning the P function:

(1) Is your "Sekinin " (or "Kakari-in") a stickler for the rules?

(2) Does your "Sekinin" (or "Kakariin ") speak about your daily " mikomi6" ?

(3) Does your "Sekinin" (or "Kakariin ") show you a new way to solve such problems as may arise in the performance of your task?

(4) How important does your "Sekinin" (or "Kakari-in") think it is to increase the efficiency and productivity of your " $\mathrm{Ka}$ $\mathrm{ta}^{7}$ "?

(5) Does your "Sekinin" (or "Kakari-in") urge you to finish your daily norm by the specified time?

(6) When you did a poor job, does your

6 "Mikomi" is estimated production quota. 
"Sekinin" (or "Kakari-in") direct criticism not so much at you as an individual as at the way you did the poor job?

(7) Does your "Sekinin " (or "Kakari-in") try to make you work to the fullest possible extent?

(8) Does your "Sekinin" (or "Kakariin ") emphasize that you should work in accordance with the working method already adopted?

Questions concerning the $M$ function :

(1) Do you think your "Sekinin" (or "Kakari-in") is not averse to listen to your opinion and suggestion?

(2) When your "Sekinin" (or "Kakariin ") disagrees with you on something, does he obtrude his opinion upon you?

(3) Does your "Sekinin" (or "Kakariin ") treat you and your co-workers equally?

(4) Does your "Sekinin" (or "Kakariin ") tend to ask your opinion about important matters concerning the work?

(5) Can you easily speak to your "Sekinin " (or "Kakari-in") about your work?

7 "Kata" means a working group which works on a shift basis. They work at the coal face for 24 hours a day in three shifts. First shift works from 7 a.m. to 3 p.m., second shift from 3 p.m. to 11 p.m., and third shift from 11 p.m. to 7 a.m. They change shifts every week. For instance, those on the first shift will be on the second shift next week.
(6) Are there times when your "Sekinin" (or "Kakari-in") makes you work without any thought to your feelings?

(7) Can you understand what your "Sekinin" (or "Kakari-in") says and does?

(8) Are there times when your "Sekinin" (or "Kakari-in) arbitrarily change "aritsuke " without consulting with you?

Separately for each question, five points are given for the most job-centered (or the most human relations-centered) responses and one point for the least job-centered (or human relations-centered) responses. Consequently, each supervisor can get somewhere between eight and forty points respectively in the $P$ and $M$ functions.

Measurement of the productivity of working groups. The productivities of two to three groups working at the same workplace were compared on the basis of the following three indices.

(I) Monthly output during the one year preceding the survey.

(2) Monthly attendance rate during the one year preceding the survey.

(3) Work efficiency as rated by sub-section chief, section chief and manager.

High-producing groups and low-producing groups were sorted out on the basis of the three

8 "Aritsuke" is assignments of coal-getters at the coal face.
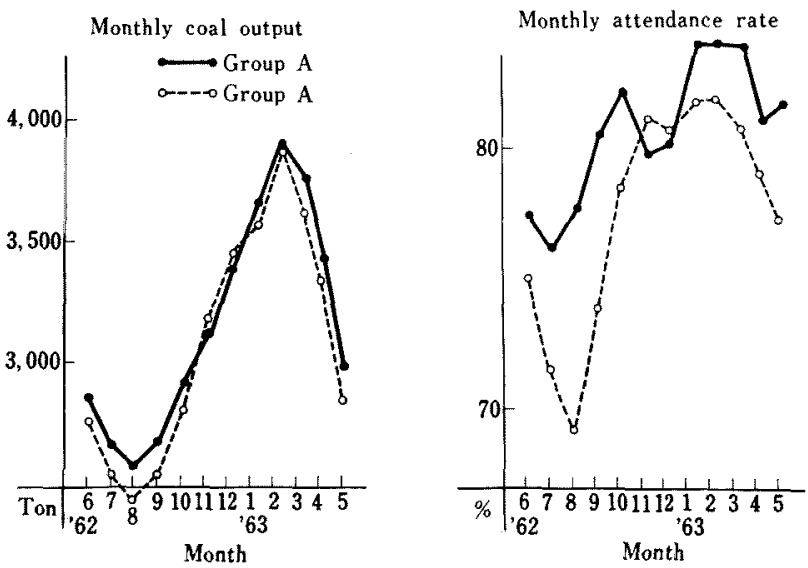

The effectiveness rating by superiors

\begin{tabular}{c|c|c}
\hline \multirow{2}{*}{ Superiors } & \multicolumn{2}{|c}{ Rating ranking } \\
\cline { 2 - 3 } & A & A $^{\prime}$ \\
\hline a & 1 & 2 \\
b & 1 & 3 \\
c & 1 & 2 \\
d & 1 & 2
\end{tabular}

Fic. 2. Monthly coal output, attendance rate for the past one year and the effectiveness rating of high-producing group $\mathrm{A}$ and low-producing group $\mathrm{A}^{\prime}$ by superiors in the workplace $\mathrm{I}$. 
indices, and only those groups which could be clearly classified either as high or low producing groups were used as the subjects for this analysis. In cases where there were three working groups in the same workplace, we used only two of them which were clearly determined either as higher-producing. Thus, 8 out of the original 19 working groups were picked as the subjects for this study.

In other words, one workplace has groups sorted as high-producing and low-producing groups respectively based on the above-mentioned three indices. Consequently, there are a total of eight groups in the four workplaces. The four workplaces are referred to as I, II, III, and IV respectively. The high-producing and low-producing groups included in each of the four workplaces are called A-A', B-B', C-C', and $D^{-} D^{\prime}$ respectively. See Fig. 2, 3, 4 and 5 .

Opinions and attitudes toward the work, working groups and supervisors. Measured according to the below-mentioned questionnaire were the degree of satisfaction with the work, group cohesiveness or attractiveness, degree of satisfaction with, and trust in, supervisors and cognitions of interrelations between the first-line su-
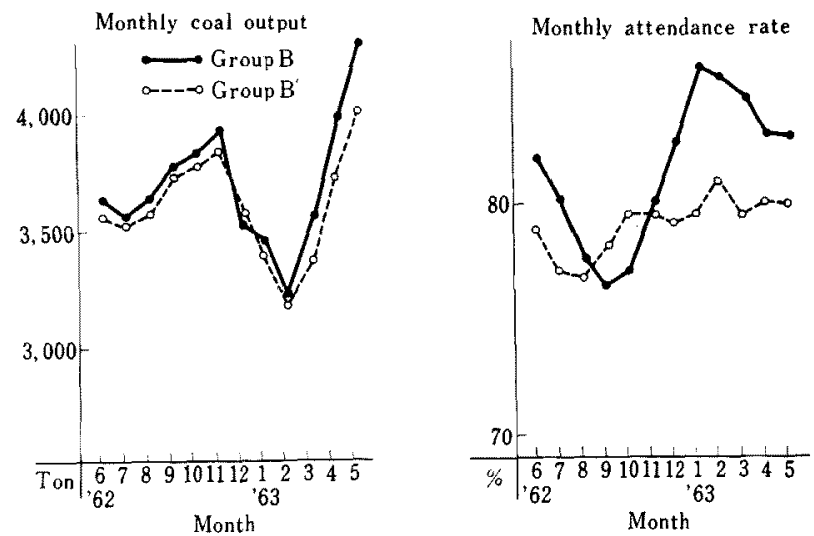

The effectiveness rating by superiors

\begin{tabular}{c|c|c}
\hline \multirow{2}{*}{ Superiors } & \multicolumn{2}{|c}{ Rating ranking } \\
\cline { 2 - 3 } & B & $\mathrm{B}^{\prime}$ \\
\hline $\mathrm{a}$ & 1 & 2 \\
$\mathrm{~b}$ & 1 & 2 \\
$\mathrm{c}$ & 1 & 3 \\
$\mathrm{~d}$ & 1 & 3
\end{tabular}

Frg. 3. Monthly coal output, attendance rate for the past one year and the effectiveness rating of high-producing group $\mathbf{B}$ and low-producing group $\mathrm{B}^{\prime}$ by superiors in the workplace II.
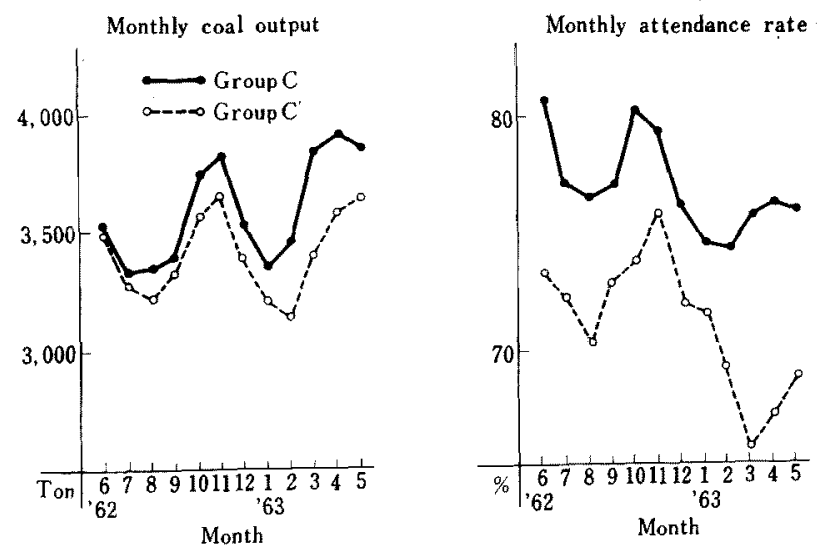

The effectiveness rating by superiors

\begin{tabular}{c|c:c}
\hline \multirow{2}{*}{ Superiors } & \multicolumn{2}{|c|}{ Rating ranking } \\
\hline & C & C \\
\hline a & I & 3 \\
b & 1 & 3 \\
c & 1 & 3 \\
d & 1 & 3 \\
& &
\end{tabular}

FIG. 4. Monthly coal output, attendance rate for the past one year and the effectiveness rating of high-producing group $\mathrm{C}$ and low-producing group $\mathrm{C}^{\prime}$ by superiors in the workplace III. 
pervisors and second-line supervisors.

(1) The degree of satisfaction with the task: Question, "Are you satisfied with your present task?"

(2) Group cohesiveness: Question, "Can you work comfortably with other workers on the same shift?"

(3) The degree of satisfaction with supervisors: Question, "Are you satisfied with working under your present 'Sekinin' (or 'Kakari-in ')?"

(4) The degree of trust in supervisors: Question, "Do you think your "Sekinin" (or 'Kakari-in') is an excellent "Sekinin' (or 'Kakari-in') compared with the one for "Mukokata'?"?

\section{Results}

1. Relationships between supervisory patterns and group productivity.

What differences were found in the behavior patterns of the first-line and secondline supervisors of the high-producing and low-producing groups in the four respective workplaces?

To begin with, it is necessary to set a criterion which serves as the dividing line between the high intensity and the low

"By "Mukokata" is meant the other working group in the same workplace. intensity of the $\mathrm{P}$ and $\mathrm{M}$ functions in order to classify operationally supervisory behaviors in terms of the $\mathrm{P}$ and $\mathrm{M}$ functions. Since each of the questions on the $P$ and $M$ functions was to be answered according to the 5-point scale, it may be proper to use the middle point as the dividing line between the high intensity and the low intensity. In this study, however, the mean scores of $\mathrm{P}$ and $\mathrm{M}$ were obtained from the cognition on the part of the workers and used as the dividing line. As stated before, 8 out of the 19 working groups were clearly determined as either high-producing or low-producing groups on the basis of the productivity indices. However, it seems more appropriate to use scores obtained from all the 19 groups in order to determine the average trend of the supervisory behaviors of this colliery as a whole in terms of $\mathrm{P}$ and $\mathrm{M}$ functional dimensions.

Table 1 shows the scores based on cognitive responses from the 500 workers as to the supervisory behaviors of the first-line and second-line supervisors.

What is meant by these mean scores is the supervisory patterns of the groups of which members were used as the subjects for this study. The average supervisory behavior of the first-line supervisor shows 25.9 in the $P$ function and 27.3 in the $M$ function.
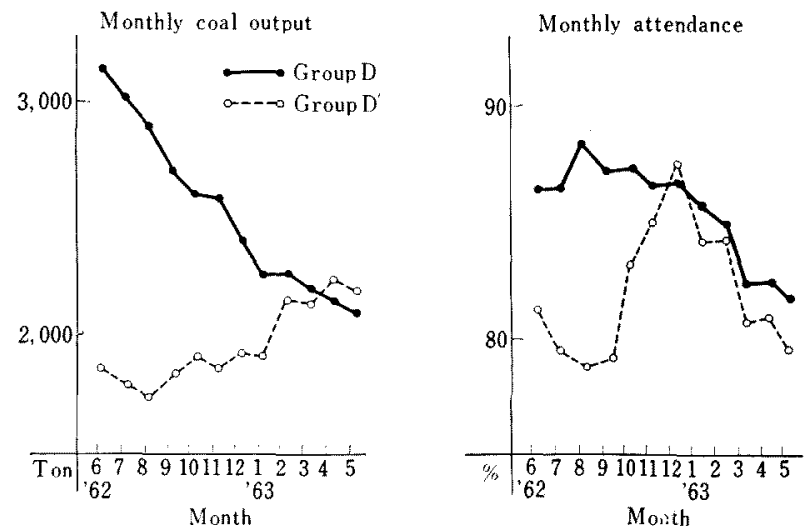

The effectiveness rating by superiors

\begin{tabular}{c|c|c}
\hline \multirow{2}{*}{ Superiors } & \multicolumn{2}{|c}{ Rating ranking } \\
\cline { 1 - 2 } & D & $\mathrm{D}^{\prime}$ \\
\hline a & 1 & 2 \\
b & 1 & 2 \\
c & 2 & 1 \\
d & 2 & 1 \\
& &
\end{tabular}

Fig. 5. Monthly coal output, attendance rate for the past one year and the effectiveness rating of high-producing group $\mathrm{D}$ and low-producing group $\mathrm{D}^{\prime}$ by superiors in the workplace IV. 
TABLE 1

Mean scores of supervisory behaviors in terms of the $\mathbf{P}$ and $\mathbf{M}$ functions

\begin{tabular}{|c|c|c|c|c|}
\hline \multirow{2}{*}{$\begin{array}{c}\text { Supervisory } \\
\text { patterns }\end{array}$} & \multicolumn{2}{|c|}{$\begin{array}{l}\text { First-line } \\
\text { Supervisors }\end{array}$} & \multicolumn{2}{|c|}{$\begin{array}{l}\text { Second-line } \\
\text { Supervisors }\end{array}$} \\
\hline & $\mathrm{P}$ & $M$ & $\mathrm{P}$ & $\mathrm{M}$ \\
\hline Mean & 25.9 & 27.3 & 26.2 & 28.2 \\
\hline$S . D$ & 1.8 & 2.7 & 2.7 & 2.3 \\
\hline
\end{tabular}

Suppose a worker gives his first-line supervisor over 25.9 points in the $P$ function, it means that he perceives his supervisor as "higher intensity" in terms of P function.

In classifying the supervisory patterns of the eight groups into P, M, PM or pm respectively, the following statistical method was employed. Calculations were made to determine what percentage of the workers in the respective groups gave more than the mean scores shown in Table 1 on the $\mathrm{P}$ functional dimension and the $\mathrm{M}$ functional dimension. When the number of the workers who gave more than the mean scores to their first-line supervisors (or second-line supervisors) on the $\mathrm{P}$ functional dimension (or $\mathrm{M}$ functional dimension) was significantly greater than that of those workers who gave less than the mean scores, the supervisory behaviors of their first-line supervisors (or second-line supervisors) were determined as pattern $\mathrm{P}$ (or pattern $M$ ). When more workers gave more than the mean scores on the $\mathrm{P}$ and $\mathrm{M}$ functional dimensions, the supervisory behaviors were classified as PM. When more workers gave less than the mean scores on both dimensions, the supervisory behaviors were classified as pm. Shown in Table 2 are the results of this survey.

Shown in Table 3 is the tabulation of the results of Table 2 as divided between the high-producing groups and the low-producing groups.

According to Table 3, both first-line and second-line supervisory patterns in all the

TABLE 2

Behavior descriptions by subordinates concerning the first-line \& second-line supervisors' behavior in terms of $P$ and $M$ functions

\begin{tabular}{|c|c|c|c|c|c|c|c|c|c|c|}
\hline \multirow{2}{*}{$\begin{array}{l}\text { Super- } \\
\text { visor }\end{array}$} & & & \multicolumn{8}{|c|}{ Working group } \\
\hline & & & $\mathrm{A}$ & $A^{\prime}$ & B & $B^{\prime}$ & $\mathrm{C}$ & $\mathrm{C}^{\prime}$ & $\mathrm{D}$ & $D^{\prime}$ \\
\hline \multirow{5}{*}{ 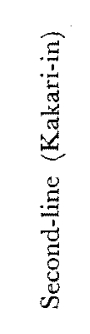 } & \multirow{3}{*}{$\mathrm{P}$} & Supervisory pattern determined & $\mathrm{pm}$ & $\mathrm{pm}$ & pm & $\mathrm{P}$ & PM & $P$ & PM & $P$ \\
\hline & & $\begin{array}{l}\text { Percentage of workers who gave more } \\
\text { than the mean scores shown in Table } 1\end{array}$ & 20.6 & 58.8 & 53.1 & $92.3^{* *}$ & *68.9* & $75.0^{*}$ & $76.4^{*}$ & $75.0^{*}$ \\
\hline & & $\begin{array}{l}\text { Percentage of workers who gave less } \\
\text { than the mean scores shown in Table } 1\end{array}$ & 79.4 & 41.2 & 46.9 & 7.7 & 31.1 & 25.0 & 23.6 & 25.0 \\
\hline & \multirow{2}{*}{$\mathbf{M}$} & $\begin{array}{l}\text { Percentage of workers who gave more } \\
\text { than the mean scores shown in Table } 1\end{array}$ & 58.6 & 25.2 & 65.6 & 53.8 & $68.9^{*}$ & 45.0 & $76.4 *$ & 25.0 \\
\hline & & $\begin{array}{l}\text { Percentage of workers who gave less } \\
\text { than the mean scores shown in Table } 1\end{array}$ & 41.4 & 64.8 & 34.4 & 46.2 & $3 \mathrm{I}, 1$ & 55.0 & 23.6 & 75.0 \\
\hline \multirow{5}{*}{ 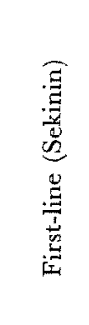 } & & Supervisory pattern determined & $\mathbf{M}$ & $\mathrm{pm}$ & $\mathrm{PM}$ & $\mathbf{P}$ & M & $P$ & $\mathrm{pm}$ & $P$ \\
\hline & \multirow{2}{*}{$\mathrm{P}$} & $\begin{array}{l}\text { Percentage of workers who gave more } \\
\text { than the mean scores shown in Table } 1\end{array}$ & 31.0 & 41.2 & $75.0^{*}$ & $69.2 *$ & 41.3 & $75.0^{*}$ & 41.1 & $75.0 *$ \\
\hline & & $\begin{array}{l}\text { Percentage of workers who gave less } \\
\text { than the mean scores shown in Table } 1\end{array}$ & 69.0 & 58.8 & 25.0 & 30.8 & 58.7 & 25.0 & 58.9 & 25.0 \\
\hline & \multirow{2}{*}{$\mathbf{M}$} & $\left\{\begin{array}{l}\text { Percentage of workers who gave more } \\
\text { than the mean scores shown in Table } 1\end{array}\right.$ & $72.4^{*}$ & 64.8 & $68.7 *$ & 61.5 & $75.8^{*}$ & 40.0 & 11.7 & 0.0 \\
\hline & & $\begin{array}{l}\text { Percentage of workers who gave less } \\
\text { than the mean scores shown in Table } 1\end{array}$ & 27.6 & 35.2 & 31.3 & 38.5 & 24.2 & 60.0 & 88.3 & 100.0 \\
\hline
\end{tabular}


TABLE 3

Relationship between the productivity and the supervisory patterns of the first-line supervisors and the second-line supervisors in the eight working groups

\begin{tabular}{|c|c|c|c|c|c|c|}
\hline \multirow{2}{*}{$\begin{array}{l}\text { Work- } \\
\text { place }\end{array}$} & \multicolumn{3}{|c|}{ High-producing group } & \multicolumn{3}{|c|}{ Low-producing group } \\
\hline & $\begin{array}{c}\text { Working } \\
\text { group }\end{array}$ & $\begin{array}{l}\text { Second-line } \\
\text { Supervisor }\end{array}$ & $\begin{array}{c}\text { First-line } \\
\text { Supervisor }\end{array}$ & $\begin{array}{l}\text { Working } \\
\text { group }\end{array}$ & $\begin{array}{l}\text { Second-lin } \\
\text { Supervisor }\end{array}$ & $\begin{array}{l}\text { First-line } \\
r \text { Supervisor }\end{array}$ \\
\hline I & A & pm & $M$ & $\mathrm{~A}^{\prime}$ & $\mathrm{pm}$ & $\mathrm{pm}$ \\
\hline II & B & pm & PM & $\mathrm{B}^{\prime}$ & $\mathbf{P}$ & $\mathrm{P}$ \\
\hline III & $\mathrm{C}$ & PM & $\mathbf{M}$ & $\mathrm{C}^{\prime}$ & $\mathbf{P}$ & $\mathrm{P}$ \\
\hline VI & $\mathrm{D}$ & PM & $\mathrm{pm}$ & $\mathbf{D}^{\prime}$ & $\mathbf{P}$ & $\mathrm{P}$ \\
\hline
\end{tabular}

low-producing groups were of pattern $\mathrm{P}$, with the only exception of the workplace I. In the case of the high-producing groups, however, no first-line or second-line supervisory behaviors of $\mathrm{P}$ were found except in the workplace I. PM was commonly found among either first-line or secondline supervisors. With the exception of the workplace I, all the low-producing groups were found to be of pattern P-P. In the case of the high-producing groups, the first-line supervisors in the workplace II were of pattern PM and the second-line supervisors pm. In the workplace IV, the situation was reverse, and the first-line supervisors were $\mathrm{pm}$ and the second-line supervisors were PM. In the workplace III, the first-line supervisors were of $M$ and the second-line supervisors PM. All this indicates that the supervisory patterns in the high-producing groups were more varied than those in the low-producing groups. Now, take the workplace I. Both first-line and second-line supervisors in the low-producing group were of pattern pm, and were weak in both $\mathrm{P}$ and $\mathrm{M}$. In the high-producing group, however, the firstline supervisory behaviors were found to be of $\mathrm{M}$ type. This constituted the difference between the high-producing group and the low-producing group.

2. Relationship between the productivity and the attitude toward task, work group and supervisors. Table 4, 5, 6, 7, 8 , and 9 show the analysis of the differences between the high-producing groups and the low-producing groups in the extent to which the workers were satisfied with their task (job), the group cohesiveness and the extent to which the workers were satisfied with, and trust, their supervisors.

As regards the extent to which the workers were satisfied with their task, it was found in the workplace III that it was significantly greater in the high-producing groups than it was in the low-producing groups. In other workplaces, however, no significant difference was found (Table 4).

The group cohesiveness in the highproducing group in the workplace III was significantly greater than that in the lowproducing group (Table 5).

In terms of the extent to which the work-

TABLE 4

The extent to which the workers are satisfied with their task in the high-producing and low-producing groups

\begin{tabular}{c|ccc}
\hline Workplace & High-producing & Low-producing \\
\hline I & pm-M & N.S & pm-pm \\
& 3.12 & & 3.30 \\
\hline II & pm-PM & N.S & P-P \\
& 3.38 & & 3.06 \\
\hline \multirow{2}{*}{ III } & PM-M & $*$ & P-P \\
& 3.50 & & 2.61 \\
\hline IV & PM-pm & N.S & P-P \\
& 3.24 & & 2.50 \\
& & & $* 0<.05)$
\end{tabular}

The higher the figure, the more satisfaction the workers have toward their task. 
TABLE 5

Group cohesiveness in the high-producing groups and low-producing groups

\begin{tabular}{|c|c|c|c|}
\hline Workplace & High-producing & & Low-producing \\
\hline \multirow{2}{*}{ I } & $\mathrm{pm}-\mathrm{M}$ & \multirow{2}{*}{ N.S } & pm-pm \\
\hline & 3.96 & & 3.62 \\
\hline \multirow{2}{*}{ II } & $\mathrm{pm}-\mathbf{P M}$ & \multirow{2}{*}{ N.S } & $\mathbf{P}-\mathbf{P}$ \\
\hline & 3.67 & & 3.97 \\
\hline \multirow{2}{*}{ III } & $\mathbf{P M}-\mathbf{M}$ & \multirow{2}{*}{$* *$} & $\mathbf{P}-\mathrm{P}$ \\
\hline & 4.28 & & 3.48 \\
\hline \multirow{3}{*}{ IV } & PM-pm & \multirow{2}{*}{ N.S } & $\mathrm{P}-\mathrm{P}$ \\
\hline & 3.59 & & 3.15 \\
\hline & & & $(* * p<.01)$ \\
\hline
\end{tabular}

The higher the figure, the greater cohesiveness there is in the group.

TABLE 6

The extent to which the workers are satisfied with their first-line supervisors in the high-producing and low-producing groups

\begin{tabular}{c|rcc}
\hline Workplace & High-producing & Low-producing \\
\hline I & pm-M & N.S & pm-pm \\
& 4.36 & & 4.31 \\
\hline II & pm-PM & N.S & P-P \\
& 3.76 & & 3.94 \\
\hline \multirow{2}{*}{ III } & PM-M & N.S & P-P \\
& 4.67 & & 3.78 \\
\hline \multirow{2}{*}{ IV } & PM-pm & & P-P \\
& 2.53 & N.S & 2.85
\end{tabular}

The higher the figure, the more satisfaction there is among the workers.

ers were satisfied with their first-line supervisors, no significant difference was found between the high-producing groups and the low-producing groups. However, as for the extent to which they trusted their firstline supervisors, it was found to be significantly greater in the high-producing group of the workplace III than it was in the low-producing group. As regards the de-
TABLE 7

The extent to which the workers trust their first-line supervisors in the high-producing and low-producing groups

\begin{tabular}{|c|c|c|c|}
\hline Workplace & High-produ & & Low-producing \\
\hline \multirow{2}{*}{ I } & $\mathrm{pm}-\mathrm{M}$ & \multirow{2}{*}{ N.S } & pm-pm \\
\hline & 4.17 & & 4.10 \\
\hline \multirow{2}{*}{ II } & pm-PM & \multirow{2}{*}{ N.S } & $\mathrm{P}-\mathrm{P}$ \\
\hline & 3.67 & & 4.06 \\
\hline \multirow{2}{*}{ III } & PM-M & \multirow{2}{*}{ ** } & $\mathbf{P}-\mathbf{P}$ \\
\hline & 4.65 & & 3.13 \\
\hline \multirow{3}{*}{ IV } & $\mathrm{PM}-\mathrm{pm}$ & \multirow{2}{*}{ N.S } & $\mathrm{P}-\mathrm{P}$ \\
\hline & 2.59 & & 2.40 \\
\hline & & & $(* * p<.01)$ \\
\hline
\end{tabular}

The higher the figure, the more trust they have toward their supervisors.

TABLE 8

The extent to which the workers are satisfied with their second-line supervisors in the highproducing and low-producing groups

\begin{tabular}{|c|c|c|c|}
\hline Workplace & High-producing & & Low-producing \\
\hline \multirow{2}{*}{ I } & $\mathrm{pm}-\mathrm{M}$ & \multirow{2}{*}{ N.S } & pm-pm \\
\hline & 4.10 & & 4.10 \\
\hline \multirow{2}{*}{ II } & $\mathrm{pm}-\mathrm{PM}$ & \multirow{2}{*}{ * } & P-P \\
\hline & 3.72 & & 3.25 \\
\hline \multirow{2}{*}{ III } & PM-M & \multirow{2}{*}{ N.S } & $\mathrm{P}-\mathrm{P}$ \\
\hline & 3.88 & & 3.83 \\
\hline \multirow{3}{*}{ IV } & PM-pm & \multirow{3}{*}{ * } & $\mathrm{P}-\mathrm{P}$ \\
\hline & 4.29 & & 2.95 \\
\hline & & & $(* p<.05)$ \\
\hline
\end{tabular}

The higher the figure, the more satisfied the workers are with their supervisors.

gree of satisfaction with their second-line supervisors, it was found to be relatively great in the high-producing groups of the workplace II and IV. As for the degree of trust in their second-line supervisors, it was found to be greater in the high-producing groups of the workplace I and IV than 
TaBle 9

The extent to which the workers trust their second-line supervisors in the highproducing and low-producing

\begin{tabular}{c|ccc}
\hline Workplace & High-producing & Low-producing \\
\hline I & pm-M & pm-pm \\
& 4.00 & & 3.55 \\
\hline II & pm-PM & N.S & P-P \\
& 3.36 & & 3.25 \\
III & PM-M & & P-P \\
& 3.31 & N.S & 3.13 \\
IV & PM-pm & $* *$ & P-P \\
& 4.25 & & 3.05 \\
& & & $(* * 0.01)$
\end{tabular}

The higher the figure, the more trust the workers have in their supervisors.

in the low-producing groups.

In what has gone before, analyses were made to determine the difference between the high-producing groups and the lowproducing groups in the extent to which the workers were satisfied with their task, the group cohesiveness and the extent to which they were satisfied with, and trust, their first-line and second-line supervisors. When each pair of high and low-producing groups from the same workplace was used as a basis of comparison, not all of the differences were significant. Neither their direction were always consistent and the expectation.

\section{Discussion}

1. In the laboratory experimental study, the second-line supervisors invariably affected the workers only indirectly. In other words, all the instructions from the second-line supervisors were conveyed only through the medium of the first-line supervisors. As a result, the supervisory patterns of the second-line supervisors were not clearly determinable through the cognitions by their subordinate workers. Con- sequently, the emphasis of the previous experimental study was placed on the $P$ and $\mathrm{M}$ functions of the first-line supervisors. Unlike in the prevous experimental study, the second-line supervisors of the industrial organization, in which this study was conducted, often made their influence directly felt on their subordinate workers. Consequently, the study of the $\mathrm{P}$ and $\mathrm{M}$ functions in supervisors was conducted without making much distinction between the firstline supervisors and the second-line supervisors. From the hierarchical point of view, the second-line supervisors are superior to the first-line supervisors, and their authority as the superior officers somewhat differs from that of the latter. However, as far as the $\mathrm{P}$ and $\mathrm{M}$ functions in their supervisory behaviors were concerned, $M$ was considered just as $M$ and $P$ was considered just as $P$, whether be it of the first-line supervisors or the second-line supervisors. In other words, the structure of an industrial organization with employees holding different hierarchical statuses was considered as one integrated group, and an attempt was made to determine, through analyses, how the supervisory behaviors of $\mathrm{P}$ or $\mathrm{M}$ type were distributed in the high-producing groups and the low-producing groups.

2. Generally speaking, the results of this study show that a supervisory pattern common to all the high-producing groups, except in the workplace I, was PM, and that one common to the low-producing groups was P. They also indicate that the degree of satisfaction or " morale " was relatively higher under PM than under P. This dovetails with the results of the previous experimental study, upon which we dwelt at some length in the foregoing "Problem " chapter.

Now, what about the workplace I? Found in the low-producing group $\mathrm{A}^{\prime}$ was only pm, while in the high-producing group A was there $M$ besides pm. What set the high-producing group and the low-producing group apart was the fact that $M$ was found in the former. 
The supervisory pattern of pm type, which multiplies lower intensity of both $\mathrm{P}$ and $\mathrm{M}$ may be interpreted as corresponding to conventional laissez-faire. It was found them that the supervisory pattern of $M$ type was more effective than such a type as laissez-faire in terms of productivity and morale.

As shown in Fig. 1, the data in the workplace $I$ resulted in the comparison of $M$ and $\mathrm{pm}$, and that in the workplaces II, III and IV resulted in the comparison of PM and $P$. From this, it follows that the results obtained from the workplace I do not conflict with those from the workplaces II, III and IV.

Thus, it may be said that the results of the previous experimental study have been definitely verified and confirmed by this study.

It has been our interpretation since the previous experimental study that it is when $\mathrm{M}$ function and $\mathrm{P}$ function are combined, thus enabling the former to give the latter a catalytic effect that they provide optimum stimulation for increment of productivity and morale. This interpretation may also be applied to the results of this study.

Furthermore, in connection with the fact newly found by this study that productivity and morale are lower under pm than under $M$, it was suggested that the effect of $P$ and $M$ functions had something to do with the intensity of $\mathbf{P}$ and $\mathrm{M}$ dimensions. ${ }^{10}$

In conventional studies of the types and functions of leadership, a bi-poler dimension with $P$ and $M$ function pole was assumed. Most of the previous studies concerning the effect of leadership patterns tended to polarize dichotomously leader-

${ }^{10}$ As further confirmed by the analytical study conducted at the Okazaki Industry Co. Ltd. immediately after this study, the effect of $P$ or $M$ is clearly correlated with its intensity. It was found that the combination of $P$ and $M$ takes effect only when the intensity of $P$ and $M$ is above a certain point and that when the intensity is below that point, i.e., when it is under the condition of $\mathrm{pm}$, the effect of the P and $M$ combination is lower than that of simple $\mathrm{P}$ or $\mathrm{M}$. ship patterns between the democratic, employee-centered and consideration-oriented leadership, on the one hand, and the despotic, authoritarian, production-centered and initiating structure-oriented leadership, on the other, thus considering the two patterns poles apart. More often than not, some of the former was regarded as a "good" leadership pattern, and some of the latter as a "bad" one. It has been reported, however, that according to the results of some study of the effect of leadership patterns, the effect of the democratic, employee-centered and consideration-oriented leadership, which was supposed to be "good", was not always superior to that of the despotic, production-centered and initiating structure-oriented leadership, which was supposed to be "bad", in terms of every criterion for evaluation. But by the same token, there seems to be no evidence to show that the latter is supeior to the former, either. ${ }^{11}$ All this points to the fact that any experimental or empirical studies concerning leadership and supervisory patterns on a dichotomous basis have come to an impasse.

In the frame of reference of our study, the supervisory pattern of pm may well be interpreted as something on the order of laissez-faire, that of $\mathrm{M}$ as something approaching an employee-centered or consideration-oriented supervisory pattern, and that of $\mathrm{P}$ as something approximation a jobcentered, despotic and initiating structureoriented supervisory pattern.

Now, what can be the most appropriate terminology for the leadership pattern of PM? It may well be called democratic leadership pattern. On the other hand, however, there is no definite proof to show that $\mathrm{M}$ is not a democratic leadership pattern. As a matter of fact, when one says democratic leadership in common parlance, he often means to emphasize the pattern

1 See Misumi J. 1965. The study of the structure and function of leadership in education and industry. Ann. Rep. of edu. Psychol, 4, 83-106. 
of $\mathrm{M}$.

\section{Summary}

With the goal achievement functional dimension and the process maintenance functional dimension used as the bases, the supervisory behaviors of the first-line supervisors and their superior second-line supervisiors in the hierarchical organization of colliery were operationally divided into four patterns: namely, P, M, and PM which is determined by the higher intensity of the functions of $P$ and $M$, plus pm in which the function of $P$ and $M$ shows the lower intensity. This study was thus designed to investigate what effect each of these supervisory patterns has on the group productivity and morale.

The $\mathrm{P}$ and $\mathrm{M}$ scores on supervisory behaviors were measured on the basis of cognitions by the workers. With 125 coalgetters used the subjects, the research was conducted by means of the group interview method, distributing questionnaire. The results can be summarized as follows.

(1) A first-line and second-line supervisory pattern common to three of the four high-producing groups was found to be that of pattern PM. The pattern $\mathrm{P}$ was found to be common to the three low-producing groups.

(2) In the fourth group, the fact that $M$ existed in the high-producing group constituted the difference from the low-producing group. Pattern pm was found to be a pattern common to all the low-producing groups.

(3) The morale of the workers in the high-producing groups was found to be relatively higher than that of those in the low-producing groups.

(4) The results of this study obviously confirmed the interpretation that it is when $P$ function and $M$ function are multiplied, thus enabling the former to give the latter a catalytic effect (into PM) that they provide optimum stimulation for increment of productivity and morale.

(5) It was revealed that the effect of $\mathrm{P}$ and $\mathrm{M}$ functions was correlated in one way or another with their intensity.

\section{References}

Besco, R., \& Lawshe, C. H. 1959 Foreman leadership as perceived by supervisors and subordinates. Personnel Psychol., 12, 573-582.

Fleishman, E. A., Harris, E., \& Burtt, H. 1955 Leadership and supervision in industry. Columbus, Ohio: Ohio State Univ., Bureau of Educational Research.

Fleishman, E. A., \& Harris, E. 1962 Patterns of leadership behavior related to employee grievance and turnover. Personnel Psychol., 15, 4356.

Halpin, A. W. 1957 The leader behavior and effectiveness of air-craft commanders. In R. W. Stogdill \& A. E. Coons (Eds.), Leader behavior; its description and measurement. Columbus, Ohio: Ohio State Univ., Bureau of Business Research.

HALPIN, A., \& WINER, B. 1952 The leadership behavior of the airplane commander. Columbus, Ohio: Ohio State Univ, Research Foundation.

Hemphile, J.K. 1957 The leader behavior associated with the administrative reputation of college departments. In R.W. Stogdill \& A. E. Coons (Eds.), Leader behavior; its description and measurement. Columbus, Ohio: State Univ., Bureau of Business Research.

KAHN, R. L. 1960 Productivity and job satisfaction. Personnel Psychol., 13, 275-287.

Misumi, J. 1960a A field study of human relations in Japanese small sized enterprises $\mathbf{I}$. Industrial Training, 6 (3), 2-12.

Misumi, J. $1960 \mathrm{~b}$ A field study of human relations in Japanese small sized enterprises II. Industrial Training, 6 (4), 2-13.

Misumi, J. \& Shirakashi, S. (in press) An experimental study of the effects of supervisory behavior on productivity and morale in hierarchical organization. Hum. Relat.

(Received Oct. 21, 1965) 